\title{
Competitive Teacher for Higher Education: Risk-Based Models of its Development
}

\author{
Valentina B. Salakhova ${ }^{1,2^{\star}}$, Alfiya R. Masalimova ${ }^{3}$, Natalia V. Belyakova ${ }^{4}$, Nataliya S. Morozova ${ }^{5}$, \\ Natalia V. Osipova ${ }^{6}$, Alexey I. Prokopyev ${ }^{7}$ \\ ${ }^{1}$ Laboratory of Humanistic Approach in Education, Moscow City University, Moscow, RUSSIA \\ 2 Department of Psychology and Pedagogy, Ulyanovsk State University, Ulyanovsk, RUSSIA \\ ${ }^{3}$ Department of Pedagogy of Higher Education, Kazan (Volga region) Federal University, Kazan, RUSSIA \\ ${ }^{4}$ Department of Pedagogy and Psychology of Professional Education, K. G. Razumovsky Moscow State University of Technologies and \\ Management (the First Cossack University), Moscow, RUSSIA \\ ${ }^{5}$ Department of Pediatric Dentistry and Orthodontics, I.M. Sechenov First Moscow State Medical University (Sechenov University), \\ Moscow, RUSSIA \\ ${ }^{6}$ Department of Public Administration and Social Technologies, Moscow Aviation Institute (National Research University), Moscow, \\ RUSSIA \\ ${ }^{7}$ Department of State and Legal Disciplines, Plekhanov Russian University of Economics, Moscow, RUSSIA
}

Received 19 March 2021 - Accepted 13 June 2021

\begin{abstract}
The significance of the research is determined by its scientific and practical significance. The modern global transformation of the world, in particular, automation, greening, the growing complexity of global risks and challenges, a network-centric society, a digital environment and many other aspects have led to the fact that the society in which the individual lives his life can rightfully be called a VUCA world. The VUCA world is a world of volatility, uncertainty, complexity and ambiguity. This is the world of "turbulent time" or "perfect storm", when all the factors complicating the situation converge at one time and at one point. Changes in the social, economic and geopolitical spheres associated with digitalization and a change in the technological structure start having a wider impact on many spheres including the education system. "Skills of the future" of both a specialist and a teacher are becoming an increasingly topical problem, while the issue related to the formation of a resource educational environment and the architectonics development of the required competences of the teacher's personality in the face of the VUCA world come to the fore in the tasks of academic science. The article is aimed at solving the problem of determining the structure, content and conditions for the implementation of pedagogical support to enhance the competitiveness of a higher education teacher for a VUCA world, as well as ensuring the effective formation of teachers' noxological competences for a VUCA world in the information and educational environment of a higher education institution. The designed pedagogical support will contribute to the effective organization of career development and professional growth of a higher education teacher for a VUCA world. The results of the study will make it possible to contribute to the development of the theory and methodology of higher education in terms of scientific substantiation and selection of the content to form a teacher's noxological competence in the information and educational environment of a higher education institution for a VUCA world. Giving a more detailed content and precise structure of the teacher's noxological competence and the proposed classification of modern risks of the educational environment will complement the theoretical foundations of pedagogical risk studies. A model of pedagogical support for the formation of noxological competences of future teachers which is to be theoretically substantiated will give an opportunity to determine the capabilities and technologies of using risk factors in pedagogical education. The expected results are believed to contribute to the solution to the problem of VUCA undertaken by the world social and humanitarian scientific community, which the modern education system in general faces and all subjects of the educational process, in particular.
\end{abstract}

Keywords: higher education institution, subjects of the educational process, competitive teacher, noxological approach, risk-oriented development models, VUCA world, digitalization of society, global risks and threats

\section{INTRODUCTION}

The modern global transformation of the world, in particular, automation, greening, the growing complexity of global risks and challenges, a networkcentric society, a digital environment and many other aspects have led to the situation when the society in which the individual lives his life can rightfully be called

(c) 2021 by the authors; licensee Modestum. This article is an open access article distributed under the terms and conditions of the Creative Commons Attribution License (http://creativecommons.org/licenses/by/4.0/). 


\section{Contribution to the literature}

- This study presents at solving the problem of determining the structure, content and conditions for the implementation of pedagogical support to enhance the competitiveness of a higher education teacher for a VUCA world.

- This study provides an analytical review of problem the competitiveness of a higher education teacher from the perspective of the teacher's personal development and a factor in the competitiveness of the educational institution of higher education and global competition in general.

- This study proves that model of pedagogical support for the formation of noxological competences of future teachers which is to be theoretically substantiated will give an opportunity to determine the capabilities and technologies of using risk factors in pedagogical education.

- The results of the study will make it possible to contribute to the development of the theory and methodology of higher education in terms of scientific substantiation and selection of the content to form a teacher's noxological competence in the information and educational environment of a higher education institution for a VUCA world.

a VUCA world. The VUCA world is a world of volatility, uncertainty, complexity and ambiguity. This is the world of "turbulent time" or "perfect storm", when all the factors complicating the situation converge at one time and at one point. Changes in the social, economic and geopolitical spheres associated with digitalization and a change in the technological structure start having a wider impact on many spheres including the education system. "Skills of the future" of both a specialist and a teacher are becoming an increasingly topical problem, while the issue related to the formation of a resource educational environment and the architectonics development of the required competences of the teacher's personality in the face of the VUCA world come to the fore in the tasks of academic science. Nevertheless, despite the spread of ideas on this problem, to date there are no studies regarding the solution to the VUCA problem, which the modern education system in general and all subjects of the educational process, in particular, face.

Higher education is a link that predetermines the formation of human capital, knowledge, technology and innovation in all sectors of the economy. The accentuation of human capital implies aspiration for a high level of competences of a graduate of a higher education institution and economic returns from the results of his work. Accordingly, the question of the effectiveness of educational activities in each educational institution of higher education and the mechanisms for achieving the quality of education is of fundamental importance. The positioning of a higher education institution on the market segment of educational services, taking account of its industry specifics, educational traditions and resource provision, makes it possible to determine the competitive advantages of each educational institution, which the teaching staff belongs to. The problem to be solved within the study at the socio-pedagogical level is determined by the fact that the existing typology of higher education institutions (federal, national research, reference, etc.) forms various scales of teacher competitiveness, identifying it by intra-university indicators. This creates new conditions for the professional activity of a higher education teacher, making it necessary to improve his own competitiveness continuously, to maintain and hold competitive positions in the field of higher education. The problem to be solved within the study at the scientific and theoretical level is determined by the need to create a pedagogical basis for the development of the competitiveness of a higher education teacher, since the concept of "competition", being in some way a situation "imposed" by market relations, complicates the professional activity of a teacher and requires continuous personal and professional development, the search for personal competitive positions while observing the standard requirements for the profession, creating a problem field for their formation and development in the operation of the educational institution of higher education (Bayanova, 2021).

The problem to be solved by the study at the scientific and practical level is expressed in the need to develop organizational and structural, personal and professional, procedural and technological mechanisms for the development of competitiveness of the teaching staff of a higher education institution (Bayanova, 2021). The solution to this problem can be achieved through the development of pedagogical support for the development of the competitiveness of a higher education teacher for a VUCA world, contributing to the effectiveness of this process.

In addition, the continuously increasing rates of development of the information and educational environment, the emergence and development of new areas in natural science, social and humanities research often border on the unwillingness and fear of society to accept and introduce new knowledge into real activity conditions. According to studies conducted by scientists (Bolotov, 2014; Devisilov, 2011; and others), the heterogeneity and inconsistency of the current situation 
causes a high degree of internal tension in society, people's susceptibility to the influence of various risk factors. As a consequence, this leads to irreversible destructive effects, which are reflected in the crisis phenomena in production, in the culture of society, a decrease in the standard of living of people, and a deterioration in their psychological and somatic status. The modernization of education, socio-economic changes in society, the expansion of opportunities for political and social choice, and the strengthening of migration processes pose the task of training a teacher who is able to foresee, prevent or compensate for the negative impact of risk factors on the educational process before the system of pedagogical education. Thus, it is necessary to take account of the content of a teacher's noxological competences at the present stage and determine the pedagogical conditions for the formation of noxological competences of teachers in the information and educational environment of a higher education institution in the face of a VUCA world (Kayumova, 2019).

In connection with the foregoing, our study is focused on solving the following contradictions:

- between the existing objective need to increase the competitiveness of higher education and insufficient emphasis on the competitiveness of a higher education teacher as a bearer of knowledge, values and ideals; between the need to innovate the system of advanced training for higher education teachers and the insufficient development of the theoretical and methodological foundations for the continuous development of their competitiveness in modern conditions; between the need to solve the problem of continuous professional improvement of teachers of higher education and the lack of development of methodological support for the development of their competitiveness, contributing to the effectiveness of this process (Bayanova, 2021);

- between the need to take account of the existing risks associated with the development of risky components of the modern educational environment, and the lack of an up-to-date classification of the risks of the modern educational process; between the increasing requirements for the level of formation of teachers' readiness to work in the risk-containing conditions of a modern higher education institution and the insufficient development of the pedagogical support of the process of forming their noxological competences; between the potential capabilities of imitation technologes in the competence-based training of graduates of pedagogical universities and the insufficient development of their application in the process of forming teachers' noxological competences (Kayumova, 2019).

The generalization of these contradictions led to the problem formulation of the research study: How to ensure the effective formation and development of teachers' competitive competences for a VUCA world in the information and educational environment of a higher education institution?

\section{THEORETICAL REVIEW}

The formation of a competitive personality of a future specialist relates to the general pedagogical problem of finding conditions, technologies, mechanisms of this pedagogical process aimed at developing personal qualities, realization of potentialities and abilities of a person (Filonchik, 2010; Resolution, 2017).

Theoretical analysis showed that (Bayanova, 2021) "in the psychological and pedagogical literature, certain aspects of the development and formation of the competitiveness of an individual in the system of professional and higher education are reflected in the works of Andreev (2013), Belonovskaya and Nevolina (2017), Saifullina and Valeeva (2019), Gilmeeva et al. (2019), Zagvyazinsky and Zakirova (1997), Kuzovlev (2000), Kuzmina (2015), Nikandrov (2000), Reshetnikov (2000), Reprintsev (2000), Slastenin (2006), Demyanchuk (2020); the use of innovative technologies in the process of forming a competitive specialist is revealed in the works of Akhmetova (2016), Grigorieva et al. (2019), Kapshutar (2012), Polat et al. (2001), Slobodchikov (2008), Shaimakova (2009), Yarmakeyev (2012); foreign experience in the formation of a competitive personality of students, graduates, specialists in humanities and engineering is disclosed in the works of Kiryakova et al. (2020), Masalimova et al. (2019), Sagitova (2011), Tregubova (2020)".

Modern conditions of higher education functioning have exacerbated the problem of its competitiveness at all levels - global, organizational, personnel, personal. The main ideas of domestic pedagogical researchers on the problem of teacher's competitiveness are highlighted in the dissertations of Vlasova (2002), Chuprova (2004), Mezinov (2009), Bibik (2016), Evplova and Zareeva (2017), Lebedev (2012), Valezhanina (2014), and Bulbulov (2014). For instance, Vlasova (2002) considers competitiveness as an individual personal characteristic based on goal-setting, value orientations, independence, psychological plasticity, stress resistance, the ability for continuous professional growth and giving advantages to the possessor in the process of employment. Chuprova (2004) defines competitiveness as "the strategic quality of the personality of a future teacher, reflecting the need for professional education to outstrip the needs of general education practice", competitiveness in her work is the result of high-quality pedagogical education. Mezinov (2009) considers competitiveness as a factor in activating the entire life of a future teacher and it is projected onto all spheres; he explores the conjugation of "socio-cultural (the context of the profession and student age) and the subjectpersonal (the context of professional and personal selfdetermination)". Bibik (2010) considers competitiveness 
as a "strategic value" of a professional, contributing to "reducing uncertainty in the life perspective", "streamlining the system of life in new socio-economic conditions" and "overcoming the individual psychological barrier"; it is based on the concept of "positive competitiveness", which implies internal (selfcompetition) and external competition in the process of interaction (cooperation / competition) (Bayanova, 2021).

Evplova and Zareeva (2017) examines the competitiveness of a teacher through the totality of his competences, analysis of activities and introspection in solving professional (quasi-professional) tasks aimed at training a highly qualified worker / specialist. Lebedev (2012) - reveals the problem of the future teacher's competitiveness through competitive advantages in the form of "general cultural, general professional, professional competences and personal characteristics"; determines the need for "continuity of stages in the development of competitiveness" and, accordingly, differentiation of variable programs for its formation and "organization of motivational and stimulating support for the development process". Valezhanina (2014) - links competitiveness with "the orientation to effective and efficient educational activities required for the formation of high working capacity of students", an increase in a teacher's labor productivity, "preserving human health, his harmonious relationship with others"; identifies two types of a teacher's competitiveness - an individual (own needs and professional aspirations) and corporate type (group or collective needs), and also shows the importance of social experience in shaping the competitiveness of a future teacher. Bulbulov (2014) defines the teacher's competitiveness as "a system, multi-level personal education, which, having projections on almost all spheres of a person's life, can act as a factor in enhancing his professional activity and become an important functional landmark of the educational process and provide an advantage in the pedagogical field in conditions of social competition". Zvonnikov and Chelyshkova (2009), in their study of the training quality of specialists, cite several variants of world models to assess professional competences: the "American model", the "British model", and the "German model" (Bayanova, 2021).

Among foreign researchers, the role of emotional, social and cognitive competences in the development of competitiveness was studied by: Pang et al. (2019), Fan et al. (2017), Ryan et al. (2009), Poon (2014), Miller et al. (2012), Dunbar et al. (2016), etc.

However, the systemic development of the subject of our study - the competitiveness of a higher education teacher for a VUCA world has not yet received sufficient theoretical and practical substantiation.

The VUCA world is a world of volatility, uncertainty, complexity and ambiguilty. In this regard, when preparing a competitive higher school teacher for a VUCA world, special attention should be paid to riskoriented models of his development.

Theoretical analysis scientific works showed that (Kayumova, 2019) safety and security issues in education are the most pressing in all countries (Health and Safety Executive reports, Great Britain; Devisilov, 2011; Kennedy et al., 2016; Kpimko \& Paranina, 2019; Moshkin, 2015; Prichinin, 2014; Sabinina, 2011).

Nurgatina (2012) writes about the need for "noxological training" of teachers and defines a noxologically oriented teacher as capable of "teaching schoolchildren to recognize, assess and predict the threats acting on humans and nature, which should become the key competence of a future teacher" (Kayumova, 2019). Educational risk is defined as a measure of the development of events in conditions of objective uncertainty in the educational system. In the works of Shabrov (2009), Bagnetova and Sharifullina (2013), risk is also defined as the likelihood of a possible manifestation of the ineffectiveness of the pedagogical process (Kayumova, 2019). In pedagogical risk studies, risk has a wide range of functions. The most successful, in our opinion, is the system of functions presented in the works of Chubarova (2005). According to Sabinina (2011), Mikhailova (2009), the risk factors associated with the modernization of education deserve special attention. The informatization of society can be called the main cause of modernization today, aimed at the formation of a person's readiness for information activities on an information basis, for the successful socialization of a person in a constantly changing, increasingly interconnected information environment - a VUCA world. The theory of pedagogical risk was developed in 1996 by Abramova (1996). She introduces the concept of justified pedagogical risk, which is understood as the sum of ideas, propositions, principles and methods of solving new problems successfully in a situation of a teacher's choice. Abramova (1999), in her work gave a classification of the types of pedagogical risks for the first time: strategic, personal, discrepancies, physical, dispositional, discrepancies, inaction, technological ones. The approach is based on the activity approach. The interaction between teachers and children was analyzed, where the unit of analysis of this interaction was risk "as a measure of the success of their joint activities" (Kayumova, 2019).

A theoretical and methodological analysis of one of the latest scientific works showed that (Kayumova, 2019) in 2009, Mikhailova (2009) investigated pedagogical risks in research and experimental activities as the most risk-bearing types of activity. The author gave a specified classification of the risks proposed by Abramova (1999) from the point of view of research and experimental activities of the teacher (with emphasis on methodological and economic risks). Mikhailova (2009) proposes a system for adapting the experience of the risk 
management program (anti-risk activities) of nonpedagogical spheres of activity into pedagogical practice (economics, management and other sciences). The risk management program includes three main stages (risk analysis, design of a risk management program, implementation of anti-risk measures).

The development and expansion of pedagogical risk studies continues in the studies of Sabinina (2008-2012). The author studies the problem of risks of innovative pedagogical activity in more detail. One of the main ideas of Sabinina's (2011) works is the close relationship between innovation and risk. Personal risks occupy a special place in the system of risks of innovative pedagogical activity, proposed by Sabinina (2011), which consists of the risks of discrepancies, change in status, temporary loss of the teacher's competence. It is noteworthy that in the works of Sabinina (2011), recommendations are also given concerning personal characteristics - the conditions for successful activity in innovative pedagogical activity. These conditions include the degree of development of the teacher's creative abilities or creativity (Sabinina, 2011). Since 2012-2014, in pedagogical risk studies, the concept of risk zones and risk management has been developing, associated with the need to "act in conditions of uncertainty". According to the International Standard "Risk Management - Principles and Guidelines", "uncertainty is a state, even partial, of a lack of information related to understanding or knowledge of events, their consequences, and likelihood" (International Standard ISO 31000, 2009). Management of the activities of any organization under conditions of uncertainty according to Vakhrusheva and Goremykina (2016) requires taking account of the existing risks (Kayumova, 2019).

A number of scientists (Belyaeva, 2014; Prichinin, 2014) consider risk management - risk management in various spheres of human activity as one of the most important objectives of contemporary education. Actually, education is an "institutional mechanism and subject of global risk management" (Kayumova, 2019).

Thus, the presented analysis of domestic and foreign literature on the problem of developing competitiveness and risk-coping behavior of a higher education teacher has shown that, despite a sufficient number of works devoted to this problem, there are no studies that reveal the structure, content and conditions of pedagogical support for the development of competitiveness and the process of forming noxological competences by a teacher in the information and educational environment of a higher education institution for a VUCA world.

In this regard, the declared research program is of particular importance for the world science, since the digitalization of society as one of the institutions of the education system today is the basis for the formation of new zones of risks and challenges. One of the causes for this phenomenon is the change in the nature of pedagogical activity. Innovation and research activities are one of the conditions for the development of the education system and at the same time a source of new risk factors and threats to pedagogical activity. These processes are an incentive for the formation of a new complex of knowledge, skills and competences of higher education teachers in the context of risks and threats to the information and educational environment of a higher education institution for a VUCA world (Kayumova, 2019; Kayumova, \& Zakirova, 2021).

\section{MATERIALS AND METHODS}

Goal of the study: to design and test the structure, content and conditions of pedagogical support for the development of competitiveness and the process of forming noxological competences of a teacher in the information and educational environment of a higher education institution for a VUCA world.

Object of the study: the process of developing competitiveness and the formation of higher education teachers' noxological competences for a VUCA world.

Subject of the study: pedagogical support for the development of competitiveness and the formation of a higher education teacher's noxological competences in the information and educational environment of a higher education institution for a VUCA world.

\section{Research Hypotheses}

1) Pedagogical support will contribute to the development of the competitiveness of a higher education teacher if it:

- is considered from the perspective of the personal development of the teacher, and, at the same time, as a factor in the competitiveness of the educational higher education institution and the global competition of the higher education system as a whole;

- provides for the use of educational resources and pedagogical potential of the higher education institution for the professional development of higher education teachers;

- systematizes and streamlines the process of developing the competitiveness of a higher education teacher, using scientifically substantiated forms, methods and technologies;

- determines the expediency of organizational and pedagogical conditions for the effective implementation of the process of developing the competitiveness of a higher education teacher (Bayanova, 2021).

2) The formation of teachers' noxological competences will be effective if the pedagogical support of this process is developed, including: 
- identifying and taking account of the structural components of the teacher's noxological competences in the process of their formation;

- interdisciplinary program to form noxological competences of a teacher based on imitation teaching technologies (Kayumova, 2019).

In accordance with the problem, object, subject, hypotheses and goal of the study, the following objectives were set:

1) to substantiate the essence, content and structure of the competitiveness of a higher education teacher in modern conditions;

2) to reveal the role and functions of the educational higher education institution in the formation of the competitiveness of a higher education teacher as his employer;

3) to develop a model of pedagogical support for the development of the competitiveness of a higher education teacher;

4) to check experimentally the effectiveness of the organizational and pedagogical conditions for the development of the competitiveness of a higher education teacher;

5) to determine the structure and content of the concept of "noxological competence of a teacher" based on the analysis of interdisciplinary approaches to the study of risks, as a basic characteristic of a teacher's readiness to work in the risk-containing educational environment;

6) to substantiate scientifically and test experimentally the model of pedagogical support for the formation of noxological competences of students-future teachers in the information and educational environment of a higher education university, taking account of the risk-containing educational environment of a modern higher education institution;

7) to develop and check experimentally the effectiveness of an interdisciplinary program for the formation of noxological competences of future teachers in the information and educational environment of a university based on imitation teaching technologies (Bayanova, 2021; Kayumova, 2019).

\section{RESULTS AND DISCUSSION}

The analysis of the research problem allowed us to develop a research program.

The theoretical and methodological foundation of the study will be laid by:

- personality-oriented paradigm of education (Leontiev, 1983, 2005; Rubinstein, 2007; Serikov, 1998; Yakimanskaya, 2010, etc.);

- the theory of competitiveness (Fatkhutdinov, 2009; McConnell \& Bru, 1999; Porter, 2016; Shvandar, 2008);
- theory of lifelong education and adult education (Abulkhanova-Slavskaya, 1991a, 1991b; Klimov, 1998; Nechaev, 1992);

- pedagogical ideas concerning the formation of the individual's competitiveness (Mitina, 2002; Shmelev, 2014) and the competitiveness of the teacher (Bibik, 2010; Chuprova, 2004; Valezhanina, 2014; Vlasova, 2002);

- positions of a competence (Bolotov, 2014; Raven, 2002; Zimnyaya, 2003), environmental (Hannanov, 2011; Manuilov, 2002), and situational approaches (Borytko, 2006; Bordovskaya \& Rean, 2008);

- features of the professional activity of a higher education teacher (Slastenin, 2006; Valeeva \& Shigapova, 2012);

- axiological approach in pedagogy (Kogan, 2011; Slastenin, 2006);

- personality-oriented approach in education (Amonashvili, 1995; Mudrik, 1996);

- a systematic approach to research in the field of education (Kraevsky, 1977; Vulfov \& Kharkin, 1995);

- environmental approach in education (Rubtsov, 2008; Slobodchikov, 2000; Yasvin, 2001);

- research in the field of risks in the training of competent personnel (Abramova, 1999; Devisilov, 2011; Mikhailova, 2009);

- studies on the application of imitation technologies in vocational education (Middlewick et al., 2012);

- the concept of humanization of education (Amonashvili, 1995; Nikandrov, 2000; Valeeva \& Shigapova, 2012);

- competence-based approach in education (Bayanova, 2021; Frumin \& Elkonin, 1993; Slobodchikov, 2008; Zimnyaya, 2003).

\section{The following methods will be used in the study:}

- theoretical methods (analysis, synthesis, generalization, comparison in the study of philosophical, psychological, sociological, pedagogical literature on the research problem);

- a modeling method for a visual representation of pedagogical support for the development of the competitiveness of a higher education teacher;

- general empirical methods;

- special empirical methods (observation, testing, questionnaires, conversation, oral and written survey; conversations with students of pedagogical programs of study, teachers of educational institutions (Test for the diagnosis coping strategies by Heim et al. (1997), Methodology "Personality orientation in communication" (Bratchenko, 1997), Test for describing the behavior of Thomas-Kilmanna (adapted by Grishina, 2008), etc.) (Kayumova, 2019); 
- methods of mathematical statistics to process research data.

Experimental research base. The research base will be composed of the following educational institutions of higher education.

The research will be conducted in three stages (our research program is based on the scientific works of Bayanova, 2021 and Kayumova, 2019):

\section{The first stage is the search and preparatory stage.}

The substantiation of the problem, theme, purpose and hypothesis of the study will be carried out; the concept of "competitiveness of a teacher of higher education " will be specified and its structural components will be identified. The state of the problem in the works of domestic and foreign scientists, the experience of organizing work on the formation of noxological competences of a future teacher in the information and educational environment of a university will be studied.

\section{Results of the research project at the first stage:}

1) The essence, content and structure of the competitiveness of a higher education teacher in modern conditions will be substantiated; the role and functions of a higher education institution in the formation of the competitiveness of a higher education teacher as his employer are going to be disclosed;

2) Based on the analysis of interdisciplinary approaches to the study of risks, is to be determined as a basic characteristic of a teacher's readiness to work in a risk-containing educational environment.

The second stage is an experimental and analytical stage.

Modeling of pedagogical support of preparation for the development of the competitiveness of a teacher of higher education will be carried out, the role of the institution of higher education in the development of the competitiveness of a higher education teacher will be determined. The development and implementation of a system for diagnostics of teachers' readiness to work in conditions of risk, a model for the formation of a teacher's noxological competence with the use of imitation technologies will be carried out; the pedagogical conditions will be identified that contribute to the effectiveness of this process.

\section{Results of the research project at the second stage:}

1) A model of pedagogical support for the development of the competitiveness of a higher education teacher is going to be designed;

2) A model of pedagogical support for the formation of noxological competences of teachers in the information and educational environment of a modern university is going to be developed and scientifically substantiated, taking account of the risk-containing educational environment of a modern higher education institution.
The third stage is a control and summarizing stage.

Experimental testing of the effectiveness of pedagogical support for the development of a higher education teacher's competitiveness will be carried out; analysis, systematization and generalization of the results obtained will be carried out; conclusions are going to be formulated and promising directions of research into the problem are going to be determined.

\section{Results of the research program at the third stage:}

1) The effectiveness of organizational and pedagogical conditions for the development of a higher education teacher's competitiveness will be experimentally proved;

2) The effectiveness of the structural-content model of pedagogical support for the formation of competitive and noxological competences of teachers in the information and educational environment of a modern higher education institution will be experimentally proved;

3) The effectiveness of an interdisciplinary program for the formation of competitive and noxological competences of teachers in the information and educational environment of a university based on imitation teaching technologies will be experimentally proved.

The results of the study will make it possible to contribute to the development of the information about the content and structure of a teacher's competitive competence and proposed classification of modern risks of the educational environment will complement the theoretical foundations of pedagogical risk studies. The pedagogical support model for the formation of teachers' competitive and noxological competences which are to be theoretically substantiated and designed structurally will give an opportunity to determine the possibilities and technologies of using risk factors in pedagogical education.

The practical significance of the research project is determined by the fact that developed pedagogical support for the competitiveness enhancement of a higher education teacher, including: a comprehensive program for the development of career strategies of a higher education teacher, organizational and pedagogical conditions and technologies for developing the competitiveness of a higher education teacher will ensure the effective implementation of pedagogical activities in the educational institution of higher education; will contribute to the education quality improvement and competitiveness of the educational institution. The designed pedagogical support for the development of a higher education teacher's competitiveness based on the results of the research project can be used in advanced training and retraining of teachers at educational institutions of higher and additional education. In addition, the theoretical ideas and conclusions developed in the course of the project 
will increase the level of formation of the teacher's noxological competence.

The research results can also be used in the system of training and professional development of primary school teachers in higher and secondary pedagogical educational institutions (Bayanova, 2021; Kayumova, 2019).

\section{The scientific newness of the study is as follows:}

1) The concept of competitiveness of a higher education teacher will be specified as an integral personal and professional characteristic, which is represented as the ability to guarantee a high-quality result of one's work, readiness for continuous professional development when the specialist is in demand by an educational institution and gets personal satisfaction from the profession.

2) The concept of "noxological competence of a teacher" will be specified as a complex of noxological knowledge, skills and abilities to act in conditions of educational environment risks.

3) A model of pedagogical support for the development of a higher education teacher's competitiveness will be developed.

4) Organizational and pedagogical conditions for the implementation of pedagogical support for the development of the competitiveness of a higher education teacher will be identified and scientifically substantiated.

5) A model of pedagogical support will be designed and substantiated to form competitive and noxological competences of teachers.

6) An interdisciplinary program will be designed and implemented to form competitive and noxological competences of teachers in the information environment of a higher education institution.

The reliability and validity of the results and conclusions obtained will be achieved by reliance on the modern methodology of scientific knowledge; multilateral analysis of the research problem; the adequacy of the proposed methods for the goal, subject and objectives of the study; representativeness of the sample size; verification of research results at different stages; qualitative and quantitative analysis of experimental data; consistency of conclusions to modern scientific ideas about the need to develop competitiveness and the formation of competitive and noxological competences of a higher education teacher (Bayanova, 2021; Kayumova, 2019).

\section{CONCLUSIONS}

Expected results of the study:

1) The competitiveness of a higher education teacher will be considered as an integral personal and professional characteristic, which represents as the ability to guarantee a high-quality result of the teacher's work, readiness for continuous professional development when the teacher is in demand from an educational institution and gets personal satisfaction from his profession. The main pedagogical characteristics of competitiveness will be determined

2) The structure of the competitiveness of a higher education teacher will be interpreted in terms of competences to establish the pedagogical potential of its formation and development, assessment criteria and diagnostic tools.

3) A model of pedagogical support for the development of competitiveness of a higher education teacher will be designed.

4) Organizational and pedagogical conditions for the implementation of the model of pedagogical support for the development of a higher education teacher's competitiveness will be determined.

5) The competitive and noxological competences of the teacher are going to be determined, which represent a complex of knowledge, skills and abilities to act in conditions of educational environment risks.

6) A model of the competitive and noxological competence formation of teachers in the information and educational environment of a modern higher education institution will be designed, consisting of the following blocks: the target component; the content component; the evaluative component.

7) An interdisciplinary program "Safe and secure educational environment" will be designed to promote the inclusion of risk factors in the educational process of a higher education institution as a component of the educational content.

The implementation of the research program, which is presented in this article, is based on the scientific research of Bayanova (2021), and Kayumova (2019). The presented results are intended to complement the scientific topic "Competitive teacher for higher education: risk-based models of its development".

Author contributions: All authors have sufficiently contributed to the study, and agreed with the results and conclusions.

Funding: No funding source is reported for this study.

Declaration of interest: No conflict of interest is declared by authors.

\section{REFERENCES}

Abramova, I. G. (1996). The theory of pedagogical risk. Russian Pedagogical University.

Abramova, I. G. (1999). Risk in teaching: theory and practice. Master, 5, 1557-1560.

Abulkhanova-Slavskaya, K. A. (1991a). Life strategy. Thought.

Abulkhanova-Slavskaya, K. A. (1991b). Within the framework of modern concepts of lifelong education. Thought. 
Akhmetova, D. Z. (2016). Universality of pedagogical knowledge from the perspective of innovations and quality of education at a modern higher educational institution. Pedagogical education and science, 2, 55-59.

Amonashvili, Sh. A. (1995). Reflections on humane pedagogy. Amonashvili Publishing House.

Andreev, V. I. (2013). Competitionology. Training course for creative self-development of competitiveness. Center for Innovative Technologies.

Bagnetova, E. A., \& Sharifullina, E. R. (2013). The occupational risks of the pedagogical environment. Fundamental Research, 1, 27-31.

Bayanova, A. R. (2021). Pedagogical support for the development of competitiveness of a teacher of higher education (PhD thesis). Kazan (Volga region) Federal University.

Belonovskaya, I. D., \& Nevolina, V. V. (2017). Professional self-development of personality as a problem of modern education. In the collection: University complex as a regional center of education, science and culture. materials of the AllRussian scientific and methodological conference. Orenburg State University, 1, 2759-2765.

Belyaeva, M. A. (2014). Risk as a subject of scientific analysis in pedagogy and education. Pedagogical education in Russia, 11, 16-23.

Bibik, I. A. (2010). Organizational and pedagogical conditions for the formation of a competitive university teacher (PhD thesis). Blagoveshchensk State Pedagogical University.

Bolotov, V. A. (2014). To the questions on the reform of pedagogical education. Psychological Science and Education, 19(3), 32-40.

Bordovskaya, N. V., \& Rean, A. A. (2008). Pedagogy. Peter.

Borytko, N. M. (2006). Diagnostic activity of the teacher. Publishing Center "Academy".

Bratchenko, S. L. (1997). Diagnostics of personalitydeveloping potential: Method. ANO.

Bulbulov, D. (2014). A systematic approach to the problem of professional development for the formation of teachers' competitiveness in the context of reforming general education in Tajikistan (PhD thesis). Academy of Education of Tajikistan.

Chubarova, O. I. (2005). Educational risk as an economic category, its essence. Polzunovsky Bulletin, 1, 199208.

Chuprova, O. F. (2004). Formation of the competitiveness of the personality of the future teacher in the process of expert and analytical activities (PhD thesis). Irkutsk State Linguistic University.
Demyanchuk, R. V. (2020). Personal and professional development of teachers and its psychological guidance (PhD thesis). Saint Petersburg State University.

Devisilov, V. A. (2011). Noxological aspects of humanization of education. Higher engineering education in Russia, 1, 129-132.

Dunbar, K. A., Laing, G., \& Wynder, M. (2016). Content analysis of accounting job advertisements: Skill requirements for graduates. E-Journal of Business Education $\mathcal{E}$ Scholarship of Teaching, 10(1), 58-72.

Evplova, E. V., \& Zareeva, T. V. (2017). Personal (individual) and corporate competitiveness of the future specialist: similarities and differences. VEGU Bulletin, 4(90), 32-40.

Fan, C. S., Wei, X., \& Zhang, J. (2017). Soft skills, hard skills, and the black or white wage gap. Economic Inquiry, 2(55), 1032-1053. https:/ / doi.org/10.1111/ ecin.12406

Fatkhutdinov, R. A. (2009). The essence of competitiveness. Modern Competition, 3, 99-129.

Filonchik, N. I. (2010). Secretion of a competitive personality indicator qualities with the engineering profile specialist. Bulletin of the Samara State Technical University. Series: Psychological and pedagogical sciences, 6(14), 171-176.

Frumin, I. D., \& Elkonin, B. D. (1993). Educational space as a developmental space ("school of growing up"). Psychological Questions, 1, 24-35.

Gafner, V. V. (2013). Safety culture: an analytical review of dissertation research (pedagogical sciences, 2002-2012): an analytical review. Ural State Pedagogical University.

Gilmeeva, R. Kh., Levina, E. Yu., Tregubova, T. M., \& Shibankov, L. A. (2019). Scientific and methodological support for the professional growth of a teacher in personnel training: scientific and methodological manual (V. E. Kozlova, S. V. Khusainova, Eds.). FGBNU Institute of Pedagogy, Psychology and Social Problems.

Grigorieva, S. G., Dementyeva, N. A., \& Ulyanova, O. V. (2019). Improvement of qualifications of teachers for the purpose of efficiency of innovative activity in an educational organization. Science and education in global processes, 1(6), 23-25.

Hannanov, R. Sh. (2011). Environmental approach in sociology. Central Russian Bulletin of Social Sciences, 1, 72-76.

Heim, E, Valach, L, Schaffner, L. (1997). Coping and psychosocial adaptation: longitudinal effects over time and stages in breast cancer. Psychosom Med, 59(4), 408-418. https:/ / doi.org/10.1097/00006842199707000-00011

International Standard ISO 31000. (2009). Risk Management - Principles and Guidelines. https:/ / iso- 
management.com/wp-content/uploads/2017/07 /ISO-31000-2009.pdf

Kapshutar, M. A. (2012). Possibilities of innovative technologies in the implementation of the axiological potential of social and humanitarian education. Topical issues of the use of innovative technologies in the educational process: Materials of the All-Russian. scientific-practical Conf. NTGSPA.

Kayumova, L. R. (2019). Formation of noxological competencies of the future teacher in the information and educational environment of the university (PhD thesis). Kazan (Volga region) Federal University.

Kayumova, L. R., \& Zakirova, V. G. (2021). The human behavioral and practical model of 'at-risk teacher training' at Kazan Federal University: Sports and educational environment. Journal of Human Sport and Exercise, 16(3proc), S1151-S1161. https://doi.org/10.14198/jhse.2021.16.Proc3.31

Kennedy, I. G., Latham, G., \& Jacinto, H. (2016). Education Skills for 21st Century Teachers. Voices from a Global Online Educators Forum. Springer. https:/ / doi.org/10.1007/978-3-319-22608-8_1

Kiryakova, A. V., Kargapoltseva, N. A., \& Belonovskaya, I. D. (2020). Scientific and pedagogical projections of the transformation of university education. Higher Education in Russia, 8(9), 155-167. https: / doi.org/10.31992/0869-3617-2020-29-8-9155-167

Klimov, S. M. (1998). Non-formal education: problems of economics and management. Knowledge.

Kogan, E. Ya. (2011). Competence approach and new quality of education. Modern approaches to competencebased education (A. V. Velikanova, Ed.). Pro.

Kpimko, N. V., \& Paranina, N. A. (2019). Development of professional competence of university students taking into account the requirements of fses $(3++)$. Teacher Education and Science, 3, 132-137.

Kraevsky, V. V. (1977). Problems of scientific substantiation of education: methodological analysis. Pedagogy.

Kuzmina, O. V. (2015). Situational approach to the study of competence in time. Bulletin of the Udmurt University, 2(25), 26-33.

Kuzovlev, V. P. (2000). Teaching at the university: science and art. Pedagogy, 1, 52-57.

Lebedev, M. S. (2012). Development of the competitiveness of future teachers in the educational process of the university (PhD thesis). Togliatti State University.

Leontiev, A. N. (1983). Selected psychological works. Pedagogy.

Leontiev, A. N. (2005). Activity. Consciousness. Personality. Meaning, Academy.

Manuilov, Yu. S. (2002). The environmental approach to education. Publishing house of the Volgo-Vyatka Academy of Public Administration.
Masalimova, A. R., Tereshchenko, A. G., \& Bubnova, I. S. (2019). Humanistic strategy of the process of modern education in higher education: psychological and pedagogical aspect. Kazan Pedagogical Journal, 5(136), 52-56. https://doi.org/ 10.34772/KPJ.2019.136.5.004

McConnell, C. R., \& Bru S. L. (1999). Economics: Principles, problems and politics. Infra-M.

Mezinov, V. N. (2009). Formation of the competitiveness of the future teacher in the educational process of the university (PhD thesis). Yelets State University named after I.A. Bunin.

Middlewick, Y., Kettle, T. J., \& Wilson, J. J. (2012). Curtains up! Using forum theatre to rehearse the art of communication in healthcare education. Nurse Education in Practice, 12(3), 139-142. https:/ / doi.org/10.1016/j.nepr.2011.10.010

Mikhailova, E. N. (2009). Riskological factors and quality of pedagog's research activities. Bulletin of Tomsk State Pedagogical University, 10, 59-63.

Miller, T., Wesley, C. L., \& Williams, D. E. (2012). Educating the minds of caring hearts: comparing the views of practitioners and educators on the importance of social entrepreneurship competencies. Academy of Management Learning $\mathcal{E}$ Education, 11(3), 349-370. https:/ / doi.org/10.5465/ amle.2011.0017

Mitina, L. M. (2002). The psychology of the development of a competitive personality. Publishing house of the Moscow Psychological and Social Institute: MODEK.

Moshkin, V. N. (2015). The upbringing of a psychological culture of safety as a pedagogical phenomenon. Bulletin of the Altai Academy of Economics and Law, 3, 120-122.

Mudrik, A. V. (1996). Individual assistance in social education. The New Values of Education, 6, 51-55.

Nechaev, V. Ya. (1992). Sociology of education. Moscow State University Publishing House.

Nikandrov, N. D. (2000). Formation of the personality of a young person in school and university: value approach. Formation of the Personality of a Young Person at School and University, 1, 6-19.

Nurgatina, I. E. (2012). The noxological basis of modern teacher's training under the conditions of social risk. Contemporary Studies of Social Problems (electronic scientific journal), 10(18), 38-52.

Pang, E., Wong M., Leung C. H., \& Coombes J. (2019). Competencies for fresh graduates success at work: Perspectives of employers. Industry and Higher Engineering Education, 33(1), 55-65. https://doi.org /10.1177/0950422218792333

Polat, E. S., Bukharkina, M. Yu., Moiseeva, M. V., \& Petrov, A. E. (2001). New pedagogical and information 
technologies in the education system. Publishing Center "Academy".

Poon, J. (2014). Do real estate courses sufficiently develop graduates' employability skills? Perspectives from multiple stakeholders. Education p Training, 56(6), 562-581. https:/ / doi.org/10.1108/ JPIF-12-2013-0068

Porter, M. E. (2016). International competition. Competitive advantages of the countries. Alpina Pabl.

Prichinin, A. E. (2014). Methodological basis of a risk management model for an educational project. Bulletin Udmurt University. Series "Philosophy. Psychology. Pedagogy ", 4, 66-75.

Raven, J. (2002). Competence in modern society: identification, development and implementation. Kogito-Center.

Reprintsev, A. V. (2000). National and universal in culture and education. KurGPU.

Reshetnikov, P. E. (2000). Professional and personal development of a teacher at the first stage of pedagogical education (PhD thesis). Belgorod State University.

Resolution. (2017). Resolution of the Government of the Russian Federation of December 26, 2017 N 1642 (as amended on March 15, 2021) "On approval of the state program of the Russian Federation" Development of education. https://www.garant. ru/products/ipo/prime/doc/71748426/

Rubinstein, S. L. (2007). Fundamentals of general psychology. Peter.

Rubtsov, V. V. (2008). Socio-genetic psychology of developmental education: an activity-based approach. MGPPU.

Ryan, G., Emmerling, R. J., \& Spencer L. M. (2009). Distinguishing high-performing European executives: the role of emotional, social and cognitive competencies. Journal of Management Development, 28(9), 859-875. https://doi.org/ 10.1108/02621710910987692

Sabinina, N. N. (2011). Risks in the teacher's innovative activity and their prevention. The World of Science, Culture, Education, 6, 85-89.

Sagitova, R. R. (2011). Formation of self-educational competence of university students in the process of studying humanitarian disciplines ( $\mathrm{PhD}$ thesis). Institute of Pedagogy and Psychology of Professional Education, Russian Academy of Education.

Saifullina, N. A., \& Valeeva, R. A. (2019). Prognostic competence of future teachers: an overview of the current state of the problem. Education and Selfdevelopment, 3(14), 140-149. https://doi.org/ $10.26907 /$ esd14.3.13

Serikov, V. V. (1998). Personality-oriented education: the search for a new paradigm. Moscow.
Shabrov, P. N. (2009). Socio-pedagogical risks as a characteristic feature of the modern Russian school. Bulletin of the Kostroma State University named after N.A. Nekrasov, 15(4), 408-412.

Shaimakova, Zh. B. (2009). The role of innovative competence in the development of competitiveness of a higher school teacher. Acmeology, 2, 38-45.

Shmelev, A. G. (2014). Competition as a metacategory of modern psychology. Part 2. Bulletin of the South Ural State University Series "Psychology", 4(7), 97-108.

Shvandar, K. V. (2008). International competitiveness: transformation of the concept, evaluation criteria, practical results. Moscow University Bulletin, 2, 5874.

Slastenin, V. A. (2006). The main trends in the development of modern educational policy in the Russian Federation. Pedagogy, 7, 20-26.

Slobodchikov, V. I. (2000). On the concept of the educational environment in the concept of developing education. Meaning.

Slobodchikov, V. I. (2008). Innovations in education: foundations and meaning. Municipal Education: Innovation and Experiment, 6, 12-15.

Tregubova, T. M. (2020). Teachers' professional development: conceptual ideas and benchmarking of best practices. Bulletin of the Chuvash State Pedagogical University named after I.Ya. Yakovleva, 2(107), 200-209. https://doi.org/10.37972/chgpu. 2020.107.2.025

Vakhrusheva, A. Yu., \& Goremykina, G. I. (2016). The concept of defining the strategy of the university's behavior in conditions of risk. International Student Scientific Bulletin, 4(4), 549-551.

Valeeva, R. A., \& Shigapova, E. M. (2012). Humanization of education: integration of the values of national traditions. Publishing house "Fatherland".

Valezhanina, T. V. (2014). Formation of the competitiveness of future teachers of vocational training in the social partnership of the university and small innovative enterprises (PhD thesis). Russian State Vocational Pedagogical University.

Vlasova, A. A. (2002). Formation of the competitiveness of future teachers. Kaliningrad State University.

Vulfov, B. Z., \& Kharkin, V. N. (1995). The pedagogy of reflection: A look at teacher professional training. ISP "Magistr Publishing House".

Yakimanskaya, I. S. (2010). The concept of studentcentered education. Scientists Notes of Petrozavodsk State University. Series. Social Sciences and Humanities, 5(110), 36-40.

Yarmakeyev, I. E. (2012). Training of innovative pedagogical personnel based on the integration of pedagogical and classical university education. Pedagogical education: current state and main directions 
of continuous pedagogical education: Materials of the International Congress. Tsitsero.

Yasvin, V. A. (2001). Educational environment: From modeling to design. Meaning.

Zagvyazinsky, V. I., \& Zakirova, A. F. (1997). Idea, plan and hypothesis of pedagogical research. Pedagogy, 3, 9-14.
Zimnyaya, I. A. (2003). Key competences - a new paradigm of the result of education. Higher engineering education today, 4, 34-42.

Zvonnikov, V. I., \& Chelyshkova M. B. (2009). Quality control of training during certification: competencebased approach. Logos.

\section{http://www.ejmste.com}

